\title{
Land-atmosphere coupling amplifies hot extremes over China
}

\author{
ZHANG Jing Yong* \& WU LingYun \\ Center for Monsoon System Research, Institute of Atmospheric Physics, Chinese Academy of Sciences, Beijing 100029, China
}

Received March 17, 2011; accepted June 14, 2011; published online August 30, 2011

\begin{abstract}
Climate extremes, such as extreme hot temperatures and heat waves, can have dramatic societal, economic, and ecological consequences. China has experienced remarkable interannual and decadal changes in hot extremes during the last several decades. However, the underlying mechanisms responsible for changes in the hot extremes over China have not been clearly identified. In this study, we investigate the role of land-atmosphere coupling for hot days and heat waves during summer over China using two long-term Weather Research and Forecasting model simulations with and without interactive soil moisture. Results indicate that land-atmosphere coupling mainly amplifies hot extremes over China. In particular, significant amplifying effects appear over most of eastern and southwestern China. Over these areas, land-atmosphere coupling generally accounts for 30\%-70\% of the numbers of hot days and heat waves. This study highlights the critical importance of land-atmosphere interactions for the occurrence of hot extremes over China.
\end{abstract}

land-atmosphere coupling, hot extremes, regional climate modeling

Citation: $\quad$ Zhang J Y, Wu L Y. Land-atmosphere coupling amplifies hot extremes over China. Chinese Sci Bull, 2011, 56: 3328-3332, doi: 10.1007/s11434-011-4628-3

In recent years, hot extremes have received increasing concerns due to their tremendous effects on human and natural systems [1,2]. A well-documented example is the European heat wave of 2003, which resulted in around 35000 heat-related deaths and major financial losses [3]. In the same summer, South China also experienced an unprecedented heat wave [4]. In the summers of 2006 and 2007, hot extremes occurred over many areas of China [5,6]. These hot extremes severely affected human health and life, energy supply and demand, water resources, and agricultural production.

Over China, hot days and heat waves have experienced remarkable interannual and decadal variations during the last several decades [7-14]. It is very likely that hot extremes will be of longer duration, more intense, and more frequent over East Asia and the globe in the future [15]. Previous studies have emphasized the importance of large-scale circulation anomalies and sea surface temperature (SST) anomalies for hot extremes over China [16,17].

*Corresponding author (email: zjy@mail.iap.ac.cn)
It is also noted that global warming and the effects of urbanization may contribute to enhance the occurrence of hot extremes $[18,19]$. Soil moisture, as a critical component of the land surface, has been recognized to play an important role in influencing surface climate [20-22]. In particular, recent studies highlighted the critical role of soil moisture for daily mean and maximum temperatures over China $[23,24]$. However, how land-atmosphere coupling affects hot extremes over China is not yet well understood.

Regional climate models have been widely used as a valuable tool to understand regional climate characteristics and change, and elucidate the mechanisms involved [25-30]. Zhang et al. [24,31] demonstrated that the Weather Research and Forecasting (WRF) model can simulate well local and regional land-atmosphere coupling compared with statistical analysis to observations and observationally based analysis data $[23,32,33]$. The objective of this study is to evaluate the role of land-atmosphere coupling for hot extremes over China by analyzing two long-term WRF model simulations with and without interactive soil moisture. 


\section{Data and method}

We use two long-term experiments with the WRF ARW version 3.1.1 [34] described by Zhang et al. [24] to isolate the role of land-atmosphere coupling for the occurrence of summer hot extremes over China. The model is a fully compressible, Euler nonhydrostatic model. The physical schemes used include the WRF single-moment six-class (WSM6) microphysics scheme [35], the Kain-Fritsch convective parameterizations [36], the Yonsei University planetary boundary layer scheme [37], the NCAR Community Atmosphere Model (CAM 3.0) spectral-band shortwave and longwave radiation schemes [38], and the unified Noah land model [39]. We use a horizontal grid resolution of $60 \mathrm{~km}$, and 28 vertical layers. The model domain centered at $36^{\circ} \mathrm{N}$ and $116^{\circ} \mathrm{E}$ covers the whole of China and surrounding areas.

A 21-year-long control simulation (CTL) with the fully coupled Noah land model allows the soil moisture to interact with the atmosphere. An additional experiment (SoilM) uses the same model configuration but disables interactive soil moisture by using prescribed climatology derived from CTL at each time step. CTL covers the period of 1 January 1979 to 31 December 1999, driven with initial and boundary conditions and SST from the National Centers for Environmental Prediction(NCEP)-Department of Energy (DOE) reanalysis [40]. Boundary conditions and SST are updated every 6 h. For SoilM, we restart CTL on 1 June and integrate to 31 August for each year of 1980-1999. The first 17 months are discarded, and we analyze the simulations for the following summers. SoilM effectively removes the effects of interactive soil moisture, and its difference with CTL can be used to quantify the contribution of land- atmosphere coupling to hot extremes over China.

In this study, we use two indices to measure hot extremes: (1) number of hot days (NHD), and (2) number of heat waves (NHW). NHD is defined as the number of the days for each grid cell in which the daily maximum temperature meets or exceeds the long-term mean 90th percentile of daily maximum temperatures. NHW is defined as the frequency of the occurrence of two or more consecutive hot days. For each of the analyzed 20 years (1980-1999), the 90th percentile is based on the 92-day period of June-August. The long-term mean 90th percentile is calculated as the mean of the 90th percentile daily maximum temperatures over the 20 years. The long-term 90th percentiles for the simulations and the observations are based on CTL and the CN05 dataset [41], respectively.

The model set-up has been evaluated with respect to its mean climate and interannual summer climate variability by Zhang et al. [24]. To evaluate simulated hot extremes of CTL, we use the $0.5^{\circ}$ gridded daily maximum temperature dataset (CN05) developed by $\mathrm{Xu}$ et al. [41]. The dataset is based on the interpolation of data from 751 observing stations in China, and it is primarily developed for the validation of climate models.

\section{Results}

To evaluate the capability of the WRF model to reproduce the observed NHD and NHW over China during 1980-1999, we compare the CTL simulation with the observations (Figure 1). The observed NHD and NHW show a similar pattern. The WRF model generally simulates NHD and NHW relatively well over eastern and southwestern China,
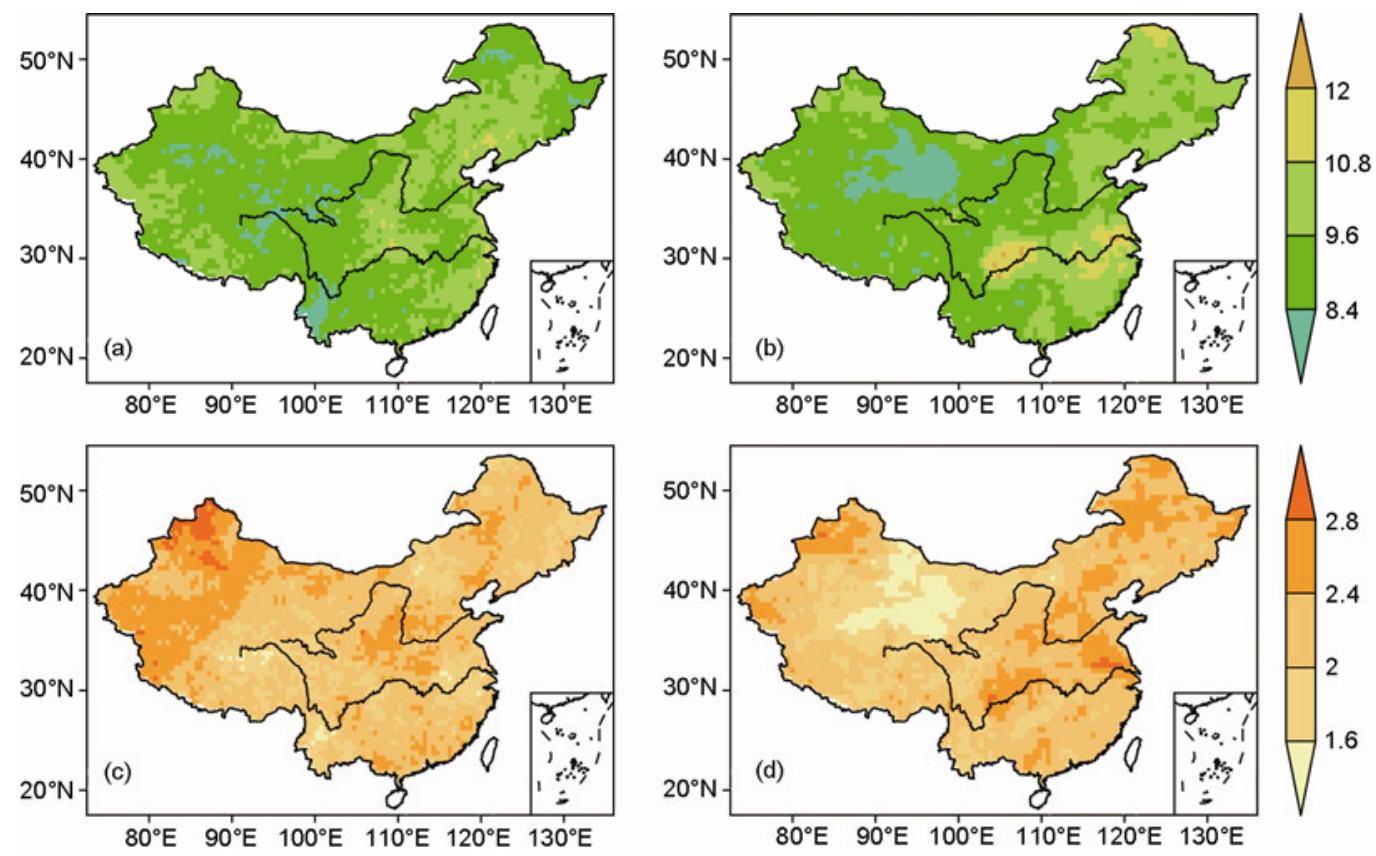

Figure 1 The 1980-1999 mean summer hot extremes in CN05 [41] (left) and CTL (right). (a), (b) NHD; (c), (d) NHW. 
both in the magnitude and spatial pattern. The model biases mainly occur over the middle and lower reaches of the Yangtze River Valley and northern part of northeastern China where both NHD and NHW are overestimated. Over northwestern China, the model reproduces well the spatial distribution of hot extremes, but underestimates the magnitudes.

The difference between CTL and SoilM represents the change induced by land-atmosphere coupling since soil moisture interactions are disabled in SoilM. Figure 2 shows that changes in NHD and NHW exhibit a very similar spatial distribution. Positive changes appear over most of China, indicating that land-atmosphere coupling mainly amplifies hot extremes. In the meanwhile, the amplifying effects depend on climate regimes. Significant increases in NHD and NHW appear over most of humid and semi-humid eastern and southwestern China, with the magnitudes of 3-7 days per year and 0.75-1.5 times per year, respectively. In contrast, over dry northwestern China, soil moisture effects are generally insignificant and much smaller though positive signs still dominate. These results are not unexpected. Soil moisture modifies surface air temperature mainly through its effects on evapotranspiration and the associated change in sensible heat flux. Zhang et al. [24] demonstrated that the coupling of soil moisture with daily mean and maximum temperatures is largely determined by the sensitivity of surface fluxes to soil moisture. Hot extremes are closely associated with daily maximum temperature. Similarly, soil moisture effects on hot extremes also depend on the ability of soil moisture to affect surface fluxes. Over regions where land-atmosphere coupling significantly amplifies hot
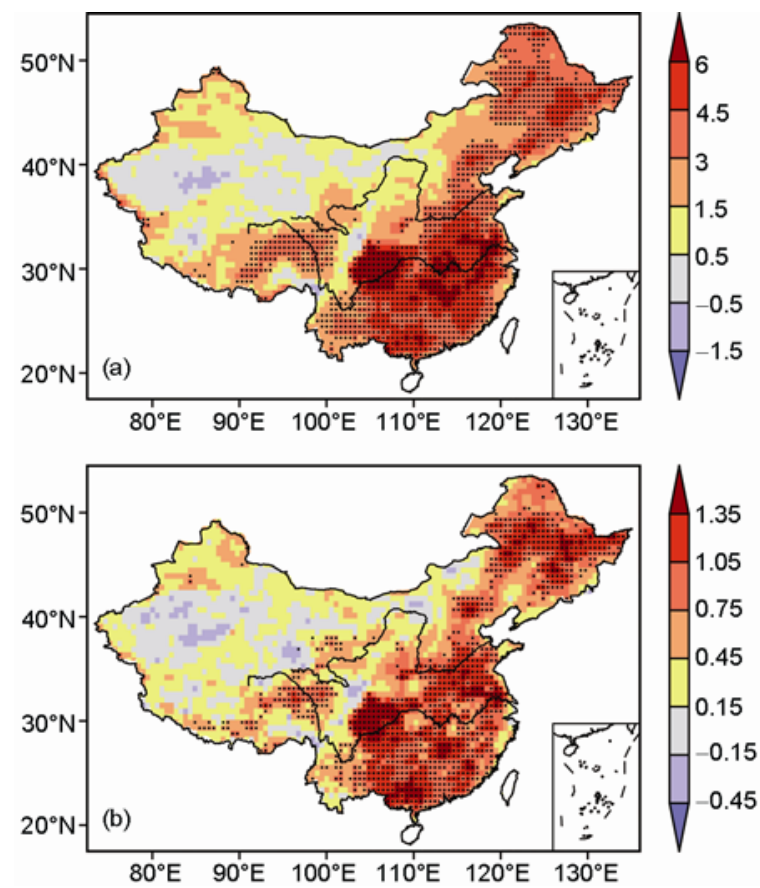

Figure 2 Differences between CTL and SoilM in NHD (a), and NHW (b). Grid cells with values significant at the $90 \%$ confidence level by Student's $t$-test are marked by solid circles. extremes, soil moisture generally exhibits a strong ability to affect surface fluxes, in particular sensible heat (see Figure 8 in [24]). In contrast, over dry northwestern China, soil moisture anomalies are too small to play an important role in influencing surface fluxes, and thus hot extremes.

We further compute the ratio of the difference in hot extremes between CTL and SoilM to the value in CTL, which reflects the relative contribution of land-atmosphere coupling to hot extremes (Figure 3). Again, a very similar spatial distribution is seen for NHD and NHW. Over most of eastern and southwestern China, where significant changes occur, land-atmosphere coupling generally accounts for $30 \%-70 \%$ of NHD and NHW. In contrast, it makes a relatively limited contribution in dry northwestern China, explaining $30 \%$ or less of hot extremes. In addition to land-atmosphere coupling, hot extremes over China can also be affected by other factors such as SST anomalies [16-19,42]. In particular over dry northwestern China, other factors may play a more important role in the occurrence of hot extremes than land-atmosphere coupling does.

\section{Conclusions}

The occurrence of hot extremes over China has been previously attributed to large-scale atmospheric circulation anomalies, SST anomalies, global warming and urbanization
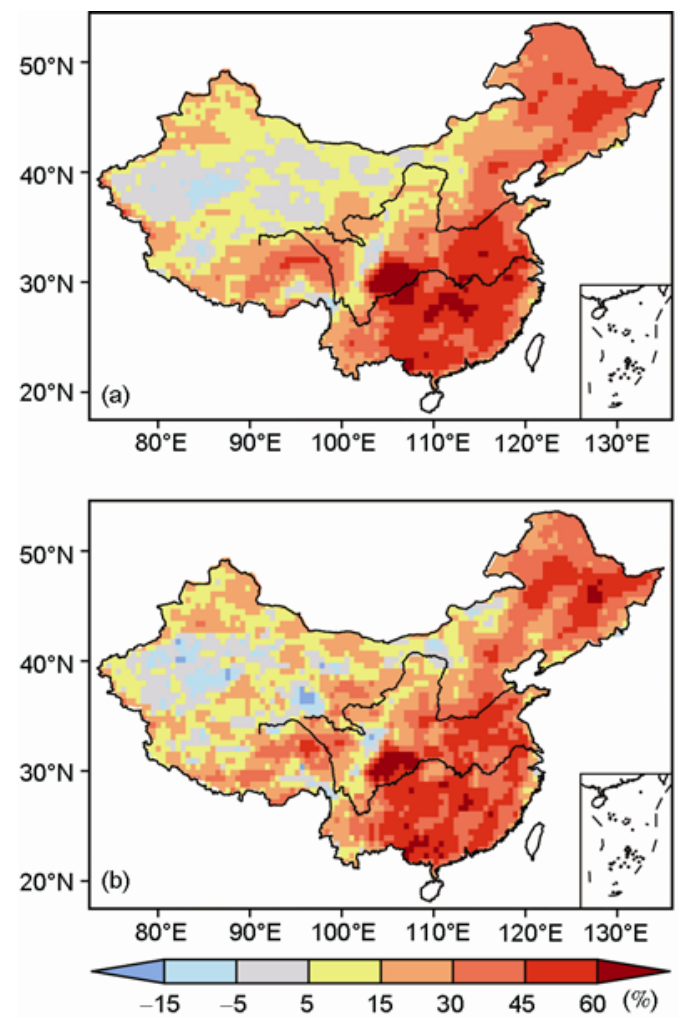

Figure 3 Percentages of NHD (a), and NHW (b) due to land-atmosphere coupling. The percentage is calculated as the ratio of the difference in NHD or NHW between CTL and SoilM to the value in CTL. 
effects [16-19]. However, the role of land-atmosphere interactions for the occurrence of hot extremes over China is not yet well understood. In this study, we take the first attempt to investigate the contribution of land-atmosphere coupling to hot extremes over China. We make two long-term WRF simulations driven with the NCEP-DOE reanalysis data: a control run covering the period 1979_ 1999 with fully interactive soil moisture, and an additional experiment repeating summer integrations for 1980-1999 but replacing soil moisture evolution at each time step with the climatology of the control run. The difference between the two experiments allows us to quantify the contribution of land-atmosphere coupling to the occurrence of hot extremes over China.

Over most of eastern and southwestern China, landatmosphere coupling significantly enhances hot extremes, accounting for $30 \%-70 \%$ of NHD and NHW. Over dry northwestern China, soil moisture is too small to play an important role in influencing surface fluxes, and thus makes a relatively limited contribution to hot extremes. The findings suggest that land-atmosphere coupling is a key player for hot extremes over most areas outside of dry northwestern China.

Generally speaking, the WRF model reproduces relatively well hot extremes over China. In the meanwhile, the model has the biases that should be recognized. For example, the model underestimates NHD and NHW over dry northwestern China, and overestimates them over the middle and lower reaches of the Yangtze River Valley and northern part of northeastern China. In the future, more studies are clearly needed to evaluate how these biases may affect simulated soil moisture feedbacks on hot extremes.

The NCEP/DOE reanalysis which is used to drive the WRF model was produced with the support of the United States National Weather Service and the PCMDI (United States Department of Energy). This work was supported by the Hundred Talents Program of the Chinese Academy of Sciences, a fund for the President's Prize of the Chinese Academy of Sciences, and the National Basic Research Program of China (2009CB421405).

1 Easterling D R, Meehl G A, Parmesan C, et al. Climate extremes: Observations, modeling, and impacts. Science, 2000, 289: 2068-2074

2 Meehl G A, Tebaldi C. More intense, more frequent, and longer lasting heat waves in the 21st century. Science, 2004, 305: 994-997

3 Luterbacher J, Dietrich D, Xoplaki E, et al. European seasonal and annual temperature variability, trends, and extremes since 1500 . Science, 2004, 303: 1499-1503

4 Yang H, Li C. Diagnostic study of serious high temperature over South China in 2003 summer (in Chinese). Clim Environ Res, 2005, 10: $80-85$

5 Chen H, Fan X. Some extreme events of weather, climate and related phenomena in 2006 (in Chinese). Clim Environ Res, 2007, 12: 100112

6 Chen H, Fan X. Some extreme events of weather, climate and related phenomena in 2007 (in Chinese). Clim Environ Res, 2008, 13: 102112

7 Ren F, Zhai P. Study on changes of China's extreme temperatures during 1951-1990 (in Chinese). Sci Atmos Sin, 1998, 22: 217-227
8 Zhai P, Sun A, Ren F, et al. Changes of climate extremes in China. Clim Change, 1999, 42: 203-218

9 Yan Z, Jones P D, Davies T D, et al. Trends of extreme temperatures in Europe and China based on daily observations. Clim Change, 2002, 53: $355-392$

10 Qian W, Lin X. Regional trends in recent temperature indices in China. Clim Res, 2004, 27: 119-134

11 Feng G, Yang J, Wan S, et al. On the prediction of record-breaking daily temperature events (in Chinese). Acta Meteorol Sin, 2009, 67: 61-74

12 Ren G, Feng G, Yan Z. Progress in observation studies of climate extremes and changes in mainland China (in Chinese). Clim Environ Res, 2010, 15: 337-353

13 Ding T, Qian W, Yan Z. Changes in hot days and heat waves in China during 1961-2007. Int J Climatol, 2010, 30: 1452-1462

14 Yan Z, Xia J, Qian C, et al. Changes in seasonal cycle and extremes in China during the period 1960-2008. Adv Atmos Sci, 2011, 28: 269-283

15 IPCC. Climate Change 2007, Working Group I Contribution to the Fourth assessment Report of the IPCC Intergovernmental Panel on Climate Change. Cambridge, New York: Cambridge University Press

16 Gong D, Pan Y, Wang J. Changes in extreme daily mean temperatures in summer in eastern China during 1955-2000. Theor Appl Climatol, 2004, 77: 25-37

17 You Q, Kang S, Aguilar E, et al. Changes in daily climate extremes in China and their connection to the large scale atmospheric circulation during 1961-2003. Clim Dyn, 2010, doi: 10.1007/s00382009-0735-0

18 Tan J, Zheng Y, Peng L, et al. Effect of heat island on heat waves in summer of Shanghai (in Chinese). Plateau Meteorol, 2008, 27: 144-149

19 Ren G, Chen Y. Global warming and changes in climate extremes over China (in Chinese). Science, 2010, 62: 30-33

20 Shukla J, Mintz Y. Influence of land-surface evapotranspiration on the Earth's climate. Science, 1982, 215: 1498-1501

21 Yeh T C, Wetherald R T, Manabe S. The effect of soil moisture on the short-term climate and hydrology change-A numerical experiment. Mon Weather Rev, 1984, 112: 474-490

22 Koster R D, Dirmeyer P A, Guo Z, et al. Regions of strong coupling between soil moisture and precipitation. Science, 2004, 305: 11381140

23 Zhang J, Dong W. Soil moisture influence on summertime surface air temperature over East Asia. Theor Appl Climatol, 2010, 100: 221226

24 Zhang J, Wu L, Dong W. Land-atmosphere coupling and summer climate variability over East Asia. J Geophys Res, 2011, 116: D05117

25 Dickinson R E, Errico R M, Giorgi F, et al. A regional climate model for the western United States. Clim Change, 1989, 15: 383-422

26 Giorgi F. Simulation of regional climate using a limited area model nested in general circulation model. J Clim, 1990, 3: 941-963

27 Leung L R, Ghan S J, Zhao Z C, et al. Intercomparison of regional climate simulations of the 1991 summer monsoon in eastern Asia. J Geophys Res, 1999, 104: 6425-6454

28 Fu C, Yuan H. An virtual numerical experiment to understand the impacts of recovering natural vegetation on the summer climate and environmental conditions in East Asia. Chinese Sci Bull, 2001, 46: 1199-1203

29 Xu Y, Zhang Y, Lin E, et al. Analyses on the climate change responses over China under SRES B2 scenario using PRECIS. Chinese Sci Bull, 2006, 51: 2260-2267

30 Gao X, Shi Y, Song Y, et al. Reduction of future monsoon precipitation over China: Comparison between a high resolution RCM and the driving GCM. Meteorol Atmos Phys, 2008, 100: 73-86

31 Zhang J, Wang W C, Leung L R. Contribution of land-atmosphere coupling to summer climate variability over the contiguous United States. J Geophys Res, 2008, 113: D22109

32 Zhang J, Wang W C, Wei J. Assessing land-atmosphere coupling using soil moisture from the Global Land Data Assimilation system and observational precipitation. J Geophys Res, 2008, 113: D17119 
33 Dirmeyer P A, Schlosser C A, Brubaker K L. Precipitation, recycling and land memory: An integrated analysis. J Hydrometeorol, 2009, 10: 1177-1198

34 Skamarock W C, Klemo J B, Dudhia J, et al. A description of the advanced research WRF version 3. Rep. NCAR/TN-475+STR, Natl Cent For Atmos Res Boulder, Colo, 2008, 125

35 Hong S Y, Lim J O J. The WRF single-moment 6-class microphysics scheme (WSM6). J Korean Meteorol Soc, 2006, 42: 129-151

36 Kain J. The Kain-Fritsch convective parameterization: An update. J Appl Meteorol, 2004, 43: 170-181

37 Hong S Y, Noh Y, Dudhia J. A new vertical diffusion package with an explicit treatment of entrainment processes. Mon Weather Rev, 2006, 134: 2318-2341

38 Collins W D, Rasch P J, Boville B A, et al. The formulation and at- mospheric simulation of the Community Atmosphere Model version 3 (CAM3). J Clim, 2006, 19: 2144-2161

39 Chen F, Dudhia J. Coupling and advanced land surface-hydrology model with the Penn State-NCAR MM5 modeling system. Part I: Model implementation and sensitivity. Mon Weather Rev, 2001, 129: 569-585

40 Kanamitsu M, Ebisuzaki W, Woollen J, et al. NCEP-DOE AMIP-II reanalysis (R-2). Bull Am Meteorol Soc, 2002, 83: 1631-1643

$41 \mathrm{Xu} \mathrm{Y,} \mathrm{Gao} \mathrm{X,} \mathrm{Shen} \mathrm{Y,} \mathrm{et} \mathrm{al.} \mathrm{A} \mathrm{daily} \mathrm{temperature} \mathrm{dataset} \mathrm{over} \mathrm{China}$ and its application in validating a RCM simulation. Adv Atmos Sci, 2009, 26: 763-772

42 Yuan Y, Yang H, Zhou W, et al. Influences of the Indian Ocean dipole on the Asian summer monsoon in the following year. Int J Climatol, 2008, 28: 1849-1859

Open Access This article is distributed under the terms of the Creative Commons Attribution License which permits any use, distribution, and reproduction in any medium, provided the original author(s) and source are credited. 